\title{
Functional analysis of the 0 antigen glucosylation gene cluster of Shigella flexneri bacteriophage SfX
}

\author{
Shukui Guan, David A. Bastin† and Naresh K. Verma
}

Division of Biochemistry and Molecular Biology, Faculty of Science, The Australian National University, Canberra, ACT 0200, Australia

\author{
Author for correspondence: Naresh K. Verma. Tel: +6126249 2666. Fax: +61262490313. \\ e-mail: Naresh.Verma@anu.edu.au
}

Keywords: LPS, O antigen serotype conversion, glucosyltransferase, bactoprenol glucose transferase, bacteriophage

\section{INTRODUCTION}

Bacterial LPS is an important outer-membrane structure which determines the bacterial somatic antigens and is important in bacterial virulence. LPS molecules consist of three regions: lipid A, which anchors the LPS in the outer membrane, a non-repeating core oligosaccharide and an $\mathrm{O}$ side chain ( $\mathrm{O}$ antigen). The genetics of $\mathrm{O}$ antigen biosynthesis have been studied in many bacteria (Clarke \& Whitfield, 1992; Ielpi et al., 1993; Jiang et al., 1991; Kessler et al., 1991; Klena \& Schnaitman, 1993; Macpherson et al., 1994; Stroeher et al., 1997). For heteropolysaccharides, such as those of Salmonella enterica and Shigella flexneri, the biosynthesis pathway is carried out by a blockwise mechanism (Schnaitman \& Klena, 1993; Whitfield, 1995). In this mechanism, O

†Present address: School of Human and Biomedical Sciences, Faculty of Applied Science, University of Canberra, ACT, Australia.

Abbreviation: UndP, undecaprenyl phosphate.

The GenBank accession number for the sequence reported in this paper is AF056939. antigen biosynthesis starts at the cytoplasmic face of the inner membrane by sequential transfer of NDP-linked sugars to a lipid carrier (undecaprenyl phosphate, UndP) to form a lipid-carrier-linked $\mathrm{O}$ antigen repeating unit, which is believed to be anchored in the cytoplasmic membrane. The repeating units are then flipped out to the periplasmic face by a very hydrophobic flippase, Wzx (formerly RfbX) (Liu et al., 1996). Polymerization occurs at the periplasmic side from the reducing end of the UndP-linked $\mathrm{O}$ side chains and is catalysed by an $\mathrm{O}$ antigen polymerase, Wzy (formerly Rfc) (McGrath \& Osborn, 1991; Morona et al., 1994; Mulford \& Osborn, 1983), in association with Wzz (formerly Rol or Cld), which regulates the length of the $\mathrm{O}$ polysaccharides (Bastin et al., 1993; Morona et al., 1995; Whitfield et al., 1997). Polymerized O side chains are then transferred from UndP to the independently synthesized core by a ligase, WaaL (formerly RfaL) (Klena et al., 1992; MacLachlan et al., 1991). The completed LPS is finally translocated to the outer membrane by a poorly understood mechanism (Muhlradt \& Golecki, 1975; Muhlradt et al., 1973). 


\section{S. flexneri serotype $Y(-: 3,4)$}

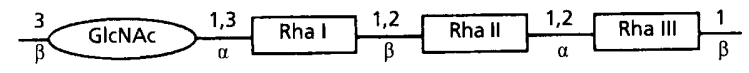

S. flexneri serotype $X(-: 7,8)$

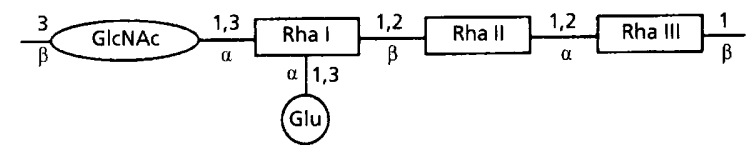

S. flexneri serotype $\mathrm{V}(\mathrm{V}: 3,4)$

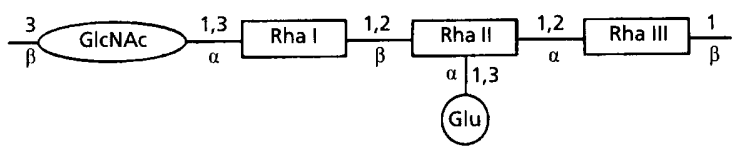

S. flexneri serotype II (II: 3,4$)$

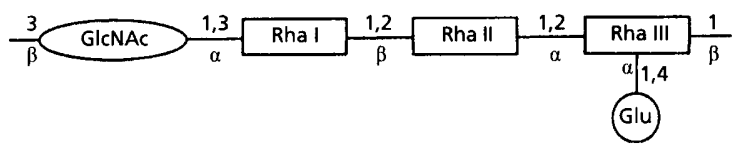

Fig. 1. Comparison of the structures of various O-specific side chain repeating units with that of a $Y$ strain. Glu, glucose; GICNAC, $\mathrm{N}$-acetylglucosamine; Rha, rhamnose. The type antigen is indicated by Roman numerals (type antigens $V$ and II) and the group antigen by Arabic numerals (group antigens 3,4 and 7,8).

Many bacteriophages which require $\mathrm{O}$ antigenic polysaccharide chains as receptors for adsorption and infection, often contain $\mathrm{O}$ antigen modification genes (Lindberg, 1977; Makela \& Stocker, 1984). These phages usually carry acetyltransferase genes, glucosyltransferase genes or novel $\mathrm{O}$ antigen polymerase systems. Upon lysogeny, these phages can modify the host bacterial $\mathrm{O}$ antigen serotype by acetylation, glucosylation or changing the mode of linkage between the repeating units, leading to the diversity of the bacterial O antigen serotype (Rogers et al., 1980; Sasaki et al., 1974; Verma et al., 1991, 1993; Wright, 1971). The modification itself is probably a protection mechanism for the prophages to exclude other homologous phages from entering lysogenized cells by altering the adsorption sites and/or may assist lysogenized cells by evading pre-existing host immunity. Earlier studies have shown that glucosylation of the LPS of Salmonella enterica involves at least two gene products which catalyse the following two steps (Makela, 1973; Nikaido et al., 1971; Nikaido \& Nikaido, 1971; Wright, 1971):

UDP- $\alpha$ Glc + lipid-P $\leftrightarrow$ lipid-P- $\beta$ Glc + UDP

Lipid-P- $\beta \mathrm{Glc}+\mathrm{O}$ antigen $\rightarrow \mathrm{O}$ antigen $-\alpha \mathrm{Glc}+$ lipid-P

The glucose substitution most likely takes place after the lipid-linked repeating units have been partially poly- merized but before the $\mathrm{O}$ antigen side chains have been transferred to the core (Takeshita \& Makela, 1971).

In $S$. flexneri, the backbone of the $\mathrm{O}$ side chains consists of a linear tetrasaccharide repeating unit: -3$)-\beta$-D-LGlcpNAc- (1-2)- $\alpha$-L-RhapI-(1-2)- $\alpha$-L-RhapII-(1-3)- $\alpha-\mathrm{L}-$

RhapIII-(1-. Bacteriophage-mediated glucosylation was found on all three rhamnose residues and also on the Nacetylglucosamine (GlcNAc) residue. Glucosylation at different sugars or at different positions on the same sugar gives rise to various group antigens (Fig. 1) (Simmons \& Romanowska, 1987). Studies of this process can potentially provide a means for development of a multivalent $S$. flexneri vaccine cocktail (effective against various serotypes) from a single parent vaccine strain. Two $S$. flexneri bacteriophage $\mathrm{O}$ antigen glucosylation systems have been recently characterized, those of $S$. flexneri phage V (SfV) and S. flexneri phage II (SfII) (Huan et al., 1997a, b; Mavris et al., 1997). A three-gene cluster was found in both these two $\mathrm{O}$ antigen glucosylation bacteriophages (Huan et al., 1997a, b; Mavris et al., 1997). The first two small genes of this three-gene cluster (referred to as $g \operatorname{tr} A$ and $g \operatorname{tr} B$ ) are nearly identical in each of the two bacteriophages, whereas the specific glucosyltransferase genes (gtrX, $g t r V$ and $g t r I I)$ are structurally similar but divergent in primary amino acid sequence. The first gene $(g \operatorname{tr} A$ in phage $\mathrm{SfV}$ ) encodes a highly hydrophobic protein of unknown function. The second gene (equivalent to $g \operatorname{tr} B$ in phage $\mathrm{SfV}$ ) of the $\mathrm{O}$ antigen glucosylation cluster of SfII has been allocated a bactoprenol glucose transferase (bgt) function based on sequence comparison (Mavris et al., 1997). Nevertheless, the functions of these three gene products have not been characterized biochemically and the supposed involvement of $g t r A$ in the modification process is still controversial. Also, the interaction between the gene products of the gtr locus and the biosynthesis pathways of $\mathrm{O}$ antigen or other bacterial cell wall components has not been investigated.

In this paper we report the molecular characterization of phage SfX, demonstrate that the first gene $(g \operatorname{tr} A)$ of the three-gene cluster most likely encodes a protein involved in the translocation of lipid-linked glucose across the cytoplasmic membrane, provide biochemical evidence to confirm that the second gene ( $g t r B)$ encodes a bactoprenol glucose transferase and propose for the first time a three-step model for the glucosylation process of $\mathrm{O}$ antigen mediated by bacteriophages of $S$. flexneri.

\section{METHODS}

Bacteria, phages and plasmids. The bacteria, phages and plasmids used in this study are listed in Table 1 . Both $S$. flexneri and Escherichia coli strains were grown at $37^{\circ} \mathrm{C}$ in Luria broth with agitation or on LB agar (Difco). For largescale phage particle preparation, NZCYM medium was used. Phage particle purification, plasmid purification, and phage and chromosomal DNA extraction were performed as described for $\lambda$ phage (Sambrook et al., 1989).

Electron microscopy of phage. Purified phage was absorbed on carbon-coated grids ( 300 mesh) and negatively stained with 
Table 1. Bacterial strains, phage and plasmids

\begin{tabular}{|c|c|c|}
\hline $\begin{array}{l}\text { Bacterial strain, } \\
\text { phage or plasmid }\end{array}$ & Relevant characteristics & Origin or reference* \\
\hline SfX & Temperate bacteriophage of $S$. flexneri & SIIDC \\
\hline S. flexneri $\mathrm{Y} 411$ & Wild-type serotype X & SIIDC \\
\hline S. flexneri SFL124 & aroD mutant of serotype $\mathrm{Y}$ & SIIDC \\
\hline S. flexneri 1195 & Derivative of SFL124: $r \mathrm{fb}^{-}$ & Falt et al. (1995) \\
\hline E. coli JM109 & $\begin{array}{l}\text { recA1 endA1 gyrA96 thi-1 hsdR17 } \\
\left(r_{\mathrm{k}}^{-}-m_{\mathrm{k}}{ }^{+}\right) \text {supE44 relA1 }\end{array}$ & Yanisch-Perron et al. (1985) \\
\hline pBluescript II $/ \mathrm{KS}+/-$ & & Stratagene \\
\hline pGP704 & Suicide vector, R6K ori & Miller \& Mekalanos (1988) \\
\hline pNV143 & $1.7 \mathrm{~kb}$ Sau3A clone harbouring $g \operatorname{tr} X$ & Verma et al. (1993) \\
\hline pNV418 & $4 \cdot 3 \mathrm{~kb}$ EcoRI clone harbouring $g \operatorname{tr} X$ & This study \\
\hline pNV57? & $\begin{array}{l}\text { gtrX (EcoRI-PstI) subcloned into a } \\
\text { suicide vector, pGP704, containing int } \\
\text { and attP from SfV }\end{array}$ & This study \\
\hline pNV 574 & gtr locus in pBluescript II/KS & This study \\
\hline pNV678 & gtrA mutant, derivative of $\mathrm{pNV} 574$ & This study \\
\hline $\mathrm{pNV} 676$ & $\begin{array}{l}\text { gtrB mutant derived from pNV574 by an } \\
\text { insertion of } 470 \text { bp exogenous DNA }\end{array}$ & This study \\
\hline pNV677 & $\begin{array}{l}\text { Derivative of pNV574, gtrX deleted by } \\
\text { Smal digestion and self-ligation }\end{array}$ & This study \\
\hline pNV679 & $\begin{array}{l}\text { Derivative of } \mathrm{pNV} 678, \mathrm{gtr} X \text { deleted by } \\
\text { SmaI digestion and self-ligation }\end{array}$ & This study \\
\hline pNV442 & $0.8 \mathrm{~kb}$ ClaI-EcoRI containing gtrA & This study \\
\hline pNV.331 & $\begin{array}{l}\text { SfV BamHI clone in pUC19, containing } \\
\text { all three genes required for O antigen } \\
\text { conversion }\end{array}$ & Huan et al. $(1997 a, b)$ \\
\hline pNV683 & $\begin{array}{l}\text { gtr } A \text { and } l a c \text { promoter from } \mathrm{pNV} 442 \text { in } \\
\text { pNV678 }\end{array}$ & This study \\
\hline pNV.341 & $\begin{array}{l}\text { gtrA and gtrB of } S \text {. flexneri phage SfV in } \\
\text { pUC19 }\end{array}$ & This study \\
\hline S. flexneri SFL1217 & $\begin{array}{l}\text { pNV577 integrated into } S \text {. flexneri } \\
\text { SFL124 chr via site-specific } \\
\text { recombination of phage SfV }: \mathrm{Km}^{\mathrm{R}}\end{array}$ & This study \\
\hline S. flexneri SFL1227 & SFL1217 carrying pNV341 & This study \\
\hline
\end{tabular}

* SIIDC, Swedish Institute for Infectious Disease Control, Stockholm, Sweden.

$2 \%(\mathrm{w} / \mathrm{v})$ sodium phosphotungstate $(\mathrm{pH} 7 \cdot 0)$. Samples were visualized with a Hitachi 600 electron microscope at $80 \mathrm{kV}$.

DNA techniques. Agarose gel electrophoresis and molecular cloning were performed by standard procedures (Sambrook et al., 1989). Transformation was performed by electroporation using a Bio-Rad Gene Pulsar. DNA sequencing was carried out by generating a series of unidirectional deletions with the Erase-a-base kit (Promega). The nucleotide sequence was determined by the dideoxy chain-termination method using the PRISM Ready Reaction Dye Primer Cycle Sequencing kit (Applied Biosystems).

LPS preparation and Western blot analysis. LPS was made according to the method of Hitchcock \& Brown (1983). Prior to loading, the LPS samples were boiled for $10 \mathrm{~min}$ in SDSPAGE loading buffer, then treated with Proteinase K (Sigma) at a final concentration of $1 \mu \mathrm{g} \mathrm{ml}^{-1}$ at $60^{\circ} \mathrm{C}$ for $1 \mathrm{~h}$ to remove protein contaminants. All samples were subjected to $9 \%$ PAGE and transferred to nitrocellulose membranes in a Tris/glycine/methanol buffer for at least $7 \mathrm{~h}$ at $100 \mathrm{~mA}$. The membranes were blocked with $1 \times$ PBS containing $5 \%(\mathrm{w} / \mathrm{v})$ skimmed milk, then incubated with serotype $X$-specific $m A b$ MASF 7,8 or with serotype Y-specific mAb MASF Y-5 for $2 \mathrm{~h}$ at room temperature. After washing thoroughly with $1 \times \mathrm{TBS}$ $(0.05 \mathrm{M}$ Tris, $0.15 \mathrm{M}$ sodium chloride, $\mathrm{pH} 7.6)$ containing $0 \cdot 1 \%$ Tween 20 , the blots were incubated with anti-mouse antibody conjugated with horseradish peroxidase (HRP) in $1 \times$ TBS containing $0 \cdot 1 \%$ Tween 20 for $1 \mathrm{~h}$ at room temperature. The bands were detected using a chemiluminescence kit (Boehringer Mannheim).

Particulate membrane preparation and enzyme assay. Membrane preparation has been described by Nikaido \& Nikaido (1971). Briefly, a $5 \mathrm{ml}$ overnight culture was diluted in $100 \mathrm{ml}$ LB (antibiotics were added where appropriate) and shaken until mid-exponential phase $\left(\mathrm{OD}_{530} \approx 1 \cdot 5\right)$. The bacteria were spun down, washed once with $100 \mathrm{ml}$ cold $0.9 \%$ saline and once with $10 \mathrm{ml}$ cold buffer A $(50 \mathrm{mM}$ Tris/acetate, $\mathrm{pH} 8.5$, $1 \mathrm{mM}$ EDTA). The cells were resuspended in $10 \mathrm{ml}$ cold buffer $A$ and sonicated $3 \times 15 \mathrm{~s}$ on ice, with a $1 \mathrm{~min}$ interval. Cell debris was removed by centrifugation at $3000 \mathrm{~g}$ for $10 \mathrm{~min}$ (Sorvall RC2, SS-34 rotor). The supernatant was spun at $111000 \mathrm{~g}$ for $20 \mathrm{~min}$ in a Beckman ultracentrifuge (SW40 
rotor). The pellet was resuspended in $0.3 \mathrm{ml}$ buffer $\mathrm{A}$ and stored at $-70{ }^{\circ} \mathrm{C}$.

The in vitro reaction mixture contained $6 \mathrm{nmol}$ decaprenyl phosphate (DP, Sigma), $50 \mathrm{mM}$ Tris/acetate ( $\mathrm{pH} \mathrm{8.5),} 10 \mathrm{mM}$ $\mathrm{MgCl}_{2}, 1 \mathrm{mM}$ EDTA, $20 \mu \mathrm{l}$ membrane fraction and $0.1 \mathrm{mM}$ UDP-D-[U- ${ }^{14} \mathrm{C}$ ]glucose $\left(7 \cdot 4 \mathrm{GBq} \mathrm{mmol}^{-1}\right.$; Amersham) in a final volume of $0.25 \mathrm{ml}$. After incubation at $37^{\circ} \mathrm{C}$ for $15 \mathrm{~min}$, the mixture was extracted twice with an equal volume of butanol. The butanol (upper phase) was combined and backextracted twice with an equal volume of distilled water. Distilled water $(0.3 \mathrm{ml})$ was added and the mixture was concentrated by drying in a vacuum concentrator (Savant). One millilitre of scintillation fluid (Packard Instruments) was added to the tube and the radioactivity was measured in a Beckman LS6500 liquid scintillation counter.

\section{RESULTS}

\section{Morphology of SfX}

Electron microscopic examination showed that SfX is a typical type $\mathrm{C}$ phage (Fig. 2), according to the morphological classification of Bradley (Ackermann \& DuBow, 1987). It strikingly resembles Salmonella bacteriophage P22 and Shigella bacteriophage Sf6. According to the criteria of the International Committee on Taxonomy of Viruses (ICTV), it should belong to the family Podoviridae (Ackermann \& DuBow, 1987). The SfX phage particle consists of an icosahedral head and a short tail. The head is around $50 \mathrm{~nm}$ in diameter and the tail is approximately $15 \mathrm{~nm}$ long.

\section{Physical map of SfX DNA}

To map SfX DNA, a variety of methods was applied, including single, double and partial endonuclease digestions and Southern hybridization. To determine

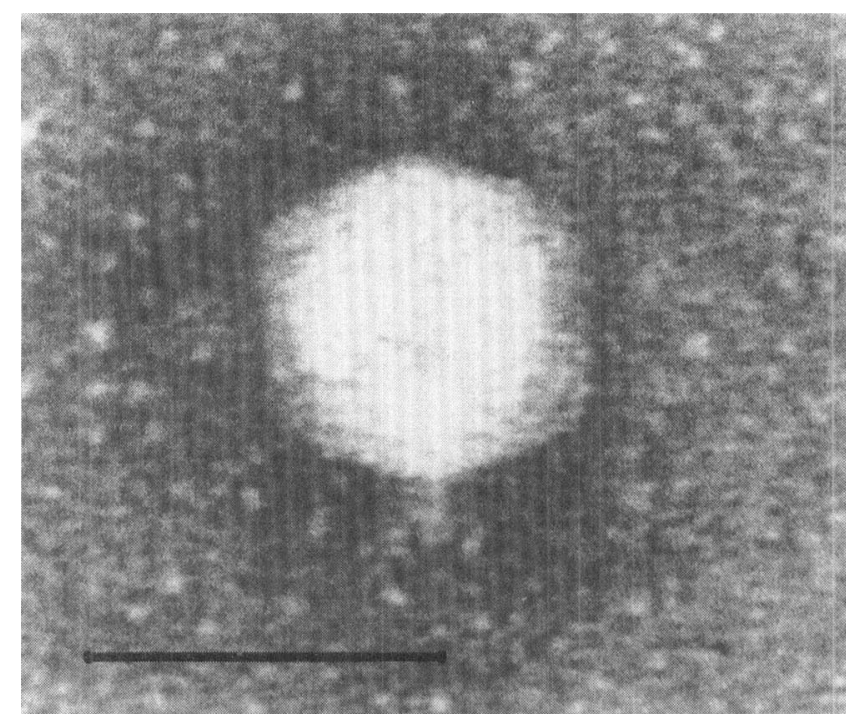

Fig. 2. Electron micrograph of bacteriophage SfX stained with $2 \%$ phosphotungstic acid. Bar, $50 \mathrm{~nm}$. whether the SfX DNA has cohesive ends or not, restriction enzyme-digested SfX DNA samples were heated to $70^{\circ} \mathrm{C}$ for $5 \mathrm{~min}$ before loading onto a gel. As no differences in the gel patterns or intensities of the bands were observed in comparison to untreated samples, we presume that SfX does not contain cohesive ends. Direct examination of SfX DNA under the electron microscope confirmed this result (data not shown). During restriction enzyme analysis, non-stoichiometric bands were observed, indicating that phage SfX DNA is likely to be encapsulated during the maturation process by the headful packaging mechanism first proposed by Streisinger et al. (1967) and modified by Tye et al. (1974). The non-stoichiometric bands are thought to represent the fragments generated between the initial packaging site and the first endonuclease cutting site, similar to the case in P22 (Jackson et al., 1978). Southern hybridization also revealed that the gel-purified smaller $B g l$ II fragment can strongly hybridize with the larger BglII fragment, indicating that phage SfX DNA may contain substantial terminal repetition. All these data suggest that SfX DNA, like that of Salmonella phage P22, is a partial circularly permuted, terminally redundant molecule and is packaged by a headful mechanism. On the basis of restriction enzyme digestion analysis, the mean size of the SfX genome was estimated to be approximately $41 \cdot 2 \mathrm{~kb}$.

\section{Genes involved in the $\mathrm{O}$ antigen conversion}

We have previously cloned the glucosyltransferase gene $(g \operatorname{tr} X)$ of SfX, which was located on a $1.7 \mathrm{~kb}$ Sau3A fragment (pNV143) (Verma et al., 1993). This clone, however, could only mediate a partial $\mathrm{O}$ antigen glucosylation when introduced into S. flexneri SFL124 (Huan et al., 1995). We have now cloned a $4.4 \mathrm{~kb}$ EcoRI fragment from the SfX genome (pNV418, Fig. 3). This clone was shown by Southern hybridization to contain the entire $1.7 \mathrm{~kb}$ phage DNA present in pNV143. However, both pNV143 and pNV418 can only partially convert a serotype $Y$ strain (group antigen - : 3,4) to a serotype $X$ strain (group antigen $-: 7,8$ ). To further investigate the genes that are required for a complete $\mathrm{O}$ antigen conversion, we cloned and sequenced the DNA fragments that are adjacent to $g \operatorname{tr} X$ from the genome of phage SfX. One clone, pNV574, was shown to mediate a full $O$ antigen conversion (Figs 3 and 4). Two smaller ORFs upstream of $g t r X$ were identified and designated $g \operatorname{tr} A$ and $g \operatorname{tr} B$ (they are highly homologous to the two smaller genes of phages SfV and SfII). Although these two genes are also present in phages SfV and SfII, which can mediate $\mathrm{O}$ antigen conversion from serotype $\mathrm{Y}$ to serotype $\mathrm{V}$ and II, respectively (Huan et al., 1997a, b; Mavris et al., 1997), the functions of the $g \operatorname{tr} A$ and $g \operatorname{tr} B$ genes in the glucosylation process have not been clearly demonstrated biochemically. In phage SfII, it was reported that only gtrB and gtrII were able to mediate a full $\mathrm{O}$ antigen conversion (Mavris et al., 1997).

To precisely locate the boundary of the gtr locus of SfX, mutations were introduced in each of these three genes 


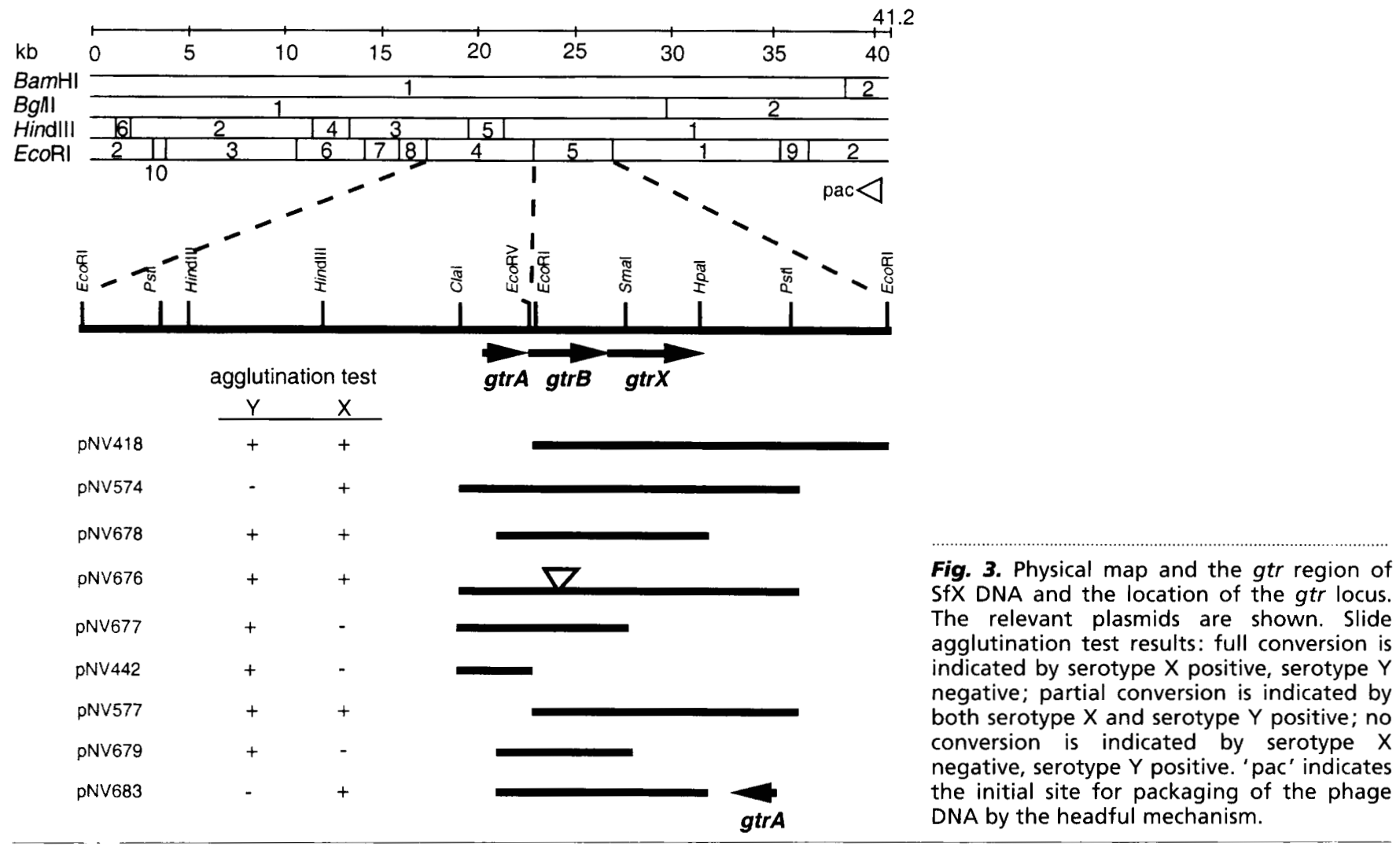

(a)

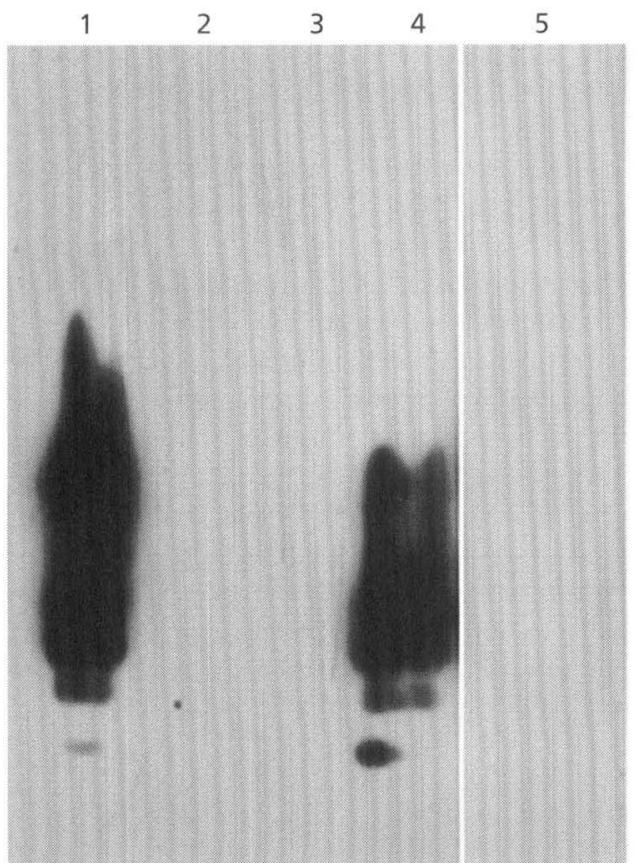

(b)

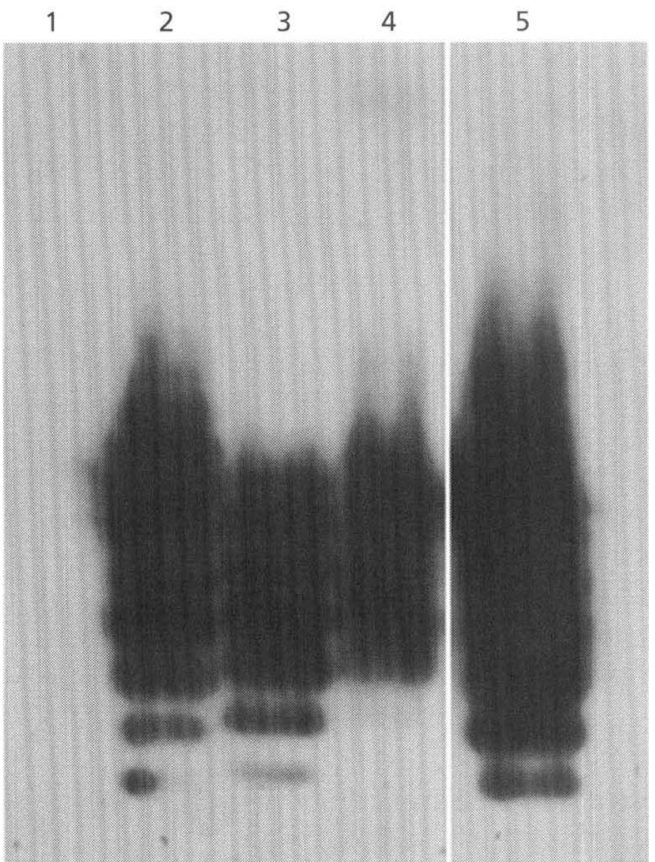

Fig. 4. Western blot analysis of LPS produced by S. flexneri strains harbouring different plasmids with mutated gtr genes. Samples were electrophoresed on a $9 \%$ SDS-PAGE gel and transferred to a nitrocellulose membrane using a glycine buffer system before incubation with serotype Y-specific mAb MASF Y-5 (a) and serotype X-specific mAb MASF 7,8 (b). Lanes: 1, S. flexneri SFL124; 2, S. flexneri Y411; 3, S. flexneri SFL124(pNV574); 4, S. flexneri SFL124(pNV678); 5, S. flexneri SFL1227. 
and the phenotype of the mutants was determined by slide agglutination and Western blot analysis using the S. flexneri serotype $\mathrm{Y}$-specific mAb (MASF Y-5) and serotype $X$-specific mAb (MASF 7,8) (Figs 3 and 4). In slide agglutination tests, partial conversion was judged by positive agglutination with both MASF 7,8 and MASF Y-5 antibodies; full conversion was judged by strong agglutination with MASF 7,8 antibody, as well as the complete loss of binding with MASF Y-5 antibody. Plasmid pNV678 is a derivative of pNV574, in which about $180 \mathrm{bp}$ of the $5^{\prime}$ end of $g \operatorname{tr} A$ has been removed. The deletion of the $5^{\prime}$-terminal half of $g \operatorname{tr} A \operatorname{did}$ not abolish the expression of $g \operatorname{tr} B$, because $g \operatorname{tr} B$ in this clone is still under the control of the lac promoter in pBluescript. Moreover, gtrB must have been expressed since the membrane fraction from this clone was able to catalyse the formation of lipid-linked glucose from UDP-Glc and lipid (see 'Function of GtrB' below). pNV678, like pNV143, can only partially convert the $O$ antigen of $S$. flexneri from a serotype $\mathrm{Y}$ strain to a serotype $\mathrm{X}$ strain, indicating that $\mathrm{gtr} A$ is necessary for a full conversion (Figs 3 and 4). To further confirm this result, an intact $\operatorname{tr} A$, preceded by a lac promoter, was inserted into the $E c l 136 \mathrm{II}$ site of $\mathrm{pNV} 678$ in the opposite orientation, giving rise to pNV683 (Fig. 3). As expected, pNV683 could mediate a full $\mathrm{O}$ antigen conversion when electroporated into SFL124, indicating GtrA is sufficient to rescue the incomplete $\mathrm{O}$ antigen conversion of pNV678 ( $g \operatorname{trB}$ and $g \operatorname{trX}$ ).

The $g \operatorname{tr} B$ gene was mutagenized by inserting $470 \mathrm{bp}$ of exogenous DNA into the unique EcoRI site of pNV574 (Fig. 3) to create pNV676. The 470 bp exogenous DNA fragment not only disrupted $g \operatorname{tr} B$, but also generated a frameshift mutation. When pNV676 was introduced into SFL124, an incomplete $\mathrm{O}$ antigen serotype conversion was observed from the slide agglutination test, indicating that $g \operatorname{tr} B$ is required for a full conversion. To confirm the function of $g t r X, p N V 574$ was cut with SmaI and self-ligated to create pNV677, in which twothirds of the $3^{\prime}$ end of $g t r X$ was deleted (Fig. 3). As predicted, this clone did not show any $\mathrm{O}$ antigen conversion activity when introduced into SFL124, indicating that $g \operatorname{tr} X$ is an absolute requirement for $\mathrm{O}$ antigen conversion. Taken together, all our results strongly suggest that all three genes in the gtr cluster of $\mathrm{SfX}$ are required for a full $\mathrm{O}$ antigen conversion, while $g \operatorname{tr} X$ alone, or in combination with either $g \operatorname{tr} A$ or $g \operatorname{tr} B$, can only mediate a partial $\mathrm{O}$ antigen conversion.

\section{Role of the glucosyltransferase (GtrX)}

A sequence comparison of the proteins encoded by $g \operatorname{tr} A$ and $g \operatorname{tr} B$ of phages SfX, SfII and SfV revealed that they are highly similar (SfX GtrA is $90 \%$ identical to SfV GtrA and $89 \%$ to SfII GtrA; SfX GtrB is $95 \%$ identical to SfV GtrB and $95 \%$ to SfII GtrB). In contrast, the protein sequences of the three phage-specific glucosyltransferases (i.e. GtrX, GtrV and GtrII) share relatively low homology. The similarity and identity scores are only 61.0 and $35.3 \%$ between SfX and SfV, and 43.8 and $19.4 \%$ between SfX and SfII, respectively. The higher similarity between GtrX and GtrV than between GtrX and GtrII probably reflects the fact that both GtrX and GtrV mediate an $\alpha-1,3$ glucosylation, whereas GtrII mediates an $\alpha-1,4$ glucosylation (Fig. 1). Nevertheless, these enzymes are all large hydrophobic proteins with 10 or more potential transmembrane domains (deduced from hydrophobicity plots), indicating their secondary structures are similar. These proteins represent a family of enzymes that catalyse similar reactions but recognize different anomeric configurations and positions of their substrates. These data encouraged us to predict that GtrX actually positions the glucosyl group onto the correct rhamnose in the $\mathrm{O}$ antigen backbone, which is the final step of the $\mathrm{O}$ antigen modification process, whereas GtrA and GtrB may just play a role in transporting the glucosyl group. Because of their high degree of similarity, the GtrA and GtrB proteins of SfX, SfV and SfII may be functionally identical and therefore, may be interchangeable.

To test this prediction, we subcloned $g t r X$ (EcoRI-Pst I) into a kanamycin-resistant derivative of the suicide vector pGP704 $\left(\mathrm{Km}^{\mathrm{R}}, \mathrm{Ap}^{\mathrm{s}}\right.$; Table 1), along with the integrase gene (int) and attachment site $(a t t P)$ of phage SfV (Huan et al., 1997a). The resulting construct (pNV577) was electroporated into SFL124, where it inserted into the bacterial chromosome via a site-specific recombination, generating strain SFL1217 $\left(\mathrm{Km}^{\mathrm{R}}, \mathrm{Ap}^{\mathrm{s}}\right)$. Upon agglutination testing, SFL1217 bound both serotype $\mathrm{Y}$ - and serotype $\mathrm{X}$-specific mAbs, indicating that gtrX can mediate a partial conversion when incorporated into the SFL124 chromosome. pNV341 is a clone that only contains $\operatorname{gtr} A$ and $\operatorname{gtr} B$ of $\mathrm{SfV}$ in an ampicillin-resistant vector. When pNV341 was electroporated into SFL1217, the kanamycin and ampicillin double-resistant strain SFL1227 (containing the chromosomally encoded $g t r X$ gene and the plasmid encoded $g \operatorname{tr} A$ and $g \operatorname{tr} B$ genes of $\mathrm{SfV}$ ) was obtained. As predicted, this strain can only agglutinate with serotype $\mathrm{X}$ mAbs and failed to agglutinate with serotype $\mathrm{V}$ or $\mathrm{Y}$ mAbs (Fig. 4). This complementation test clearly demonstrated that GtrA and GtrB do not determine the specificity of the glucosylation. They are probably only involved in the glucosyl group translocation process and are interchangeable between phages SfX and SfV. The final positioning of the glucosyl group to the sugar residue is determined only by the glucosyltransferase (GtrX or $\mathrm{GtrV})$.

\section{Function of GtrB}

It has recently been proposed that $g \operatorname{tr} B$ in the gtr cluster of SfII encodes a bactoprenol glucosyltransferase, which catalyses the transfer of glucosyl from UDP glucose to bactoprenol - a lipid carrier for the translocation of oligosaccharide precursor molecules across the cytoplasmic membrane. To determine its biochemical function, we have carried out in vitro enzyme assays using an $S$. flexneri $\mathrm{O}$ antigen-negative mutant SFL1195, which is 
Table 2. Incorporation of $\left[{ }^{14} \mathrm{C}\right]$ glucose into total butanol soluble fraction

\begin{tabular}{|lcl|}
\hline Strain & {$\left[{ }^{14} \mathrm{C}\right]$ Glucose (c.p.m.)* } & \multicolumn{1}{c|}{ Gene } \\
\hline SFL1195(pNV574) & 18616 & gtrA gtrB gtrX \\
SFL1195(pNV678) & 15091 & gtrB gtrX \\
SFL1195(pNV679) & 14700 & gtrB \\
SFL1195(pNV677) & 8572 & gtrA gtrB \\
SFL1195(pNV442) & $73 \cdot 6$ & gtrA \\
SFL1195(pNV676) & $134 \cdot 6$ & gtrA gtrX \\
SFL1195 & $90 \cdot 6$ & - \\
\hline
\end{tabular}

* Mean of a duplicate result with freshly prepared particulate membrane fractions.

a derivative of SFL124. Particulate membrane fractions obtained from SFL1195 and its derivatives carrying various plasmids were incubated with exogenously supplied decaprenyl phosphate [DP (Sigma), functionally similar to UndP] and UDP- $\left[{ }^{14} \mathrm{C}\right]$ glucose, in a reaction described in Methods. Because of the lack of an $\mathrm{O}$ antigen receptor for the glucosyl group in this strain, the accumulation of radioactivity in the butanolsoluble portion should represent the amount of the DPlinked $\left[{ }^{14} \mathrm{C}\right]$ glucose intermediate. As shown in Table 2, membrane fractions from all strains possessing gtrB resulted in significantly high amounts of $\left[{ }^{14} \mathrm{C}\right]$ glucose incorporation (varying from 8572 to 18600 c.p.m.). Noticeably, the incorporation of radioactivity generated by the membrane preparation containing GtrB and GtrA (8572 c.p.m.) is lower than those generated by other GtrB-containing membrane preparations (14700-18816 c.p.m.). This is primarily due to the fact that the SFL1195-containing plasmid pNV677 (gtrA and gtrB) grew extremely slowly and the membrane fraction prepared from this strain contained significantly less GtrB. Nonetheless, the membrane preparation from this strain still resulted in a radioactivity incorporation at least 60 times higher than that from any gtrB-negative derivative strains of SFL1195. In contrast, membrane from the parent strain, SFL1195, and strains lacking gtrB only resulted in very low background radioactivity (ranging from 30 to 140 c.p.m.). These experiments were repeated several times and data obtained were reproducible. Taken together, these results clearly demonstrated that $g \operatorname{tr} B$ is the structural gene of the enzyme that catalyses the formation of the lipid-linked glucose intermediate from UndP and UDP-glucose. Based on sequence comparisons, conservative motif sequences (DXSXD and DXD), which were present in a number of glycosyltransferases, were identified in GtrB (Mavris et al., 1997). It should be noted that the conservative motif in GtrB is the signature sequence of $\beta$-glucosyltransferases (Amor \& Whitfield, 1997; Keenleyside \& Whitfield, 1996), indicating that GtrB can form $\beta$-glucosidic bonds. This is in agreement with the result that the linkage in the lipid-P-Glc intermediate is in the $\beta$-configuration (Nikaido \& Nikaido, 1971). This means that the configuration of the glucosyl molecules is changed twice during the glucosylation process (from UDP- $\alpha$ Glc to lipid- $\beta$ Glc and to $O$ antigen- $\alpha$ Glc). In addition, the bactoprenol-glucose-transferasepositive results of plasmids pNV678 and pNV679 in SFL1195 also confirmed the expression of $g \operatorname{tr} B$ in these two plasmids, most likely under the lac promoter. However, only the functional $g \operatorname{tr} B$ and $g \operatorname{tr} X$ were insufficient for a full $\mathrm{O}$ antigen conversion in SFL124.

\section{GtrA and GtrB cause bacterial cell lysis}

Sequence analysis revealed that $\operatorname{gtr} A$ encodes a highly hydrophobic protein with four potential transmembrane domains. Such a small protein $(13 \cdot 2 \mathrm{kDa})$ containing four transmembrane domains is uncommon. Although $g \operatorname{trA}$ was also found in the gtr loci of phages $\mathrm{SfV}$ and SfII, the function of this protein remains unknown. The highly hydrophobic nature of GtrA suggests that it may play a role in the translocation of UndP-Glc across the cytoplasmic membrane. Moreover, we noticed that the recombinant strain grew considerably slower than the parent strain SFL124 and lysed when resuspended in $30 \mathrm{mM}$ Tris $/ \mathrm{HCl}(\mathrm{pH} 8.0)$ when only $g \operatorname{tr} A$ and $g \operatorname{tr} B$ (pNV677) were introduced into SFL124. This phenomenon was first noticed when LPS was prepared from this strain. Later, we found that it is also sensitive to other low osmolarity solutions, such as $1 \times$ PBS. The lysis phenomenon was quantitatively tested with a spectrophotometer. The results showed that after $30 \mathrm{mM}$ Tris $/ \mathrm{HCl}$ treatment on ice for $30 \mathrm{~min}$, the $\mathrm{OD}_{600}$ dropped significantly for SFL124(pNV677) (from 1.64 to $0.78)$, whereas SFL124 remained constant. This result was consistently obtained when this experiment was repeated.

In another experiment, the bacteria were diluted in $\mathrm{LB}$ before and after the $30 \mathrm{mM}$ Tris/ $\mathrm{HCl}$ treatment, plated out on LB plates and the colonies were counted the next day. The number of colonies for SFL124(pNV677) dropped approximately 10 -fold after the treatment. In contrast, no change in colony numbers was observed with SFL124 after this treatment. To further investigate which gene was responsible for this phenotype, we separately cloned gtrA and $\operatorname{gtr} B$ of phage SfX into pBluescript (Fig. 3), generating pNV442 and pNV679, respectively. These two constructs were individually introduced into SFL124. To our surprise, neither of the two plasmids alone could cause cell lysis, as pNV676 
did, although pNV679 (gtrB) caused limited cell lysis. $g \operatorname{tr} A$ and $g \operatorname{tr} B$ of phage $\mathrm{SfV}$ were also cloned and subsequently introduced into SFL124, and were also able to make the host strain susceptible to low osmolarity solutions. We therefore concluded that GtrB was responsible for cell lysis and the lytic action was enhanced when both genes were present.

\section{DISCUSSION}

In this paper, we have shown that the $\mathrm{O}$ antigen conversion mediated by phage SfX requires three genes. Gene gtrA encodes a small hydrophobic protein, which might play a role in the translocation of lipid-linked glucose across the cytoplasmic membrane. gtrB encodes a bactoprenol glucosyltransferase and $g t r X$ encodes a serotype X-specific glucosyltransferase. Similar structures were also found in two other S. flexneri serotype-converting bacteriophages, SfV and SfII (Huan et al., 1997a, b; Mavris et al., 1997). Interestingly, two genes homologous to $S$. flexneri phage gtrA and $g \operatorname{tr} B$ were also found in the newly released E. coli $\mathrm{K}-12$ complete genome sequence (ECAE000323, section 213 of 400; Blattner et al., 1997). A third gene located downstream of the gtrAB homologues had similar secondary structure to the $S$. flexneri phage gtr genes. This three-gene cluster is preceded by an ORF whose product (accession no. g1788690) is nearly identical to the integrase of S. flexneri phage Sf6. In addition, a number of other proteins encoded by genes downstream of this three-gene cluster in the E. coli chromosome were also found to be similar to bacteriophage proteins. In particular, o114, the putative product of the gene immediately downstream of the putative gtr cluster, is $36 \%$ identical to protein 0194 of phage $\lambda$ (accession no. Y194-LAMBD), the function of which is thought to be in phage tail fibre assembly. The product of the sixth gene downstream of the putative gtr cluster (f122, accession no. g1788700), shows $48 \%$ identity to the phage $\lambda \mathrm{O}$ protein, which is involved in phage replication. All these data suggest that this segment of DNA of the E. coli chromosome most likely represents a remnant or cryptic phage and the gtr-like three-gene locus is well conserved in this remnant or cryptic phage. Salmonella bacteriophages P22 and epsilon 34, and chromosomeencoded factor $12_{2}$ glucosylation clusters probably also contain three genes. In earlier studies using in vitro enzyme assays, it was not possible to distinguish a $\operatorname{gtr} A$ mutation from a gtr $B$ mutation, because particulate membrane fractions from both mutants retain the ability to transfer the glucosyl group from purified lipid-Glc to LPS. Therefore, it is not surprising that a two-step mechanism involving two enzymes was proposed (Makela, 1973; Nikaido et al., 1971; Nikaido \& Nikaido, 1971; Wright, 1971). We believe that a threegene cluster may be a common feature for $\mathrm{O}$ antigen glucosylation systems.

It has been proposed that glucosylation of Salmonella LPS takes place at the step after the repeat units have been synthesized and partially polymerized, while still linked to UndP (Takeshita \& Makela, 1971). As the polymerization occurs on the periplasmic face of the cytoplasmic membrane, translocation of the glucose residues from the cytoplasmic side to the periplasmic side of the inner membrane is essential for GtrX to correctly position the glucose residue. GtrB only contains two hydrophobic domains, which may be used to anchor the protein to the cytoplasmic membrane. The major part of this protein should be retained on the cytoplasmic face of the cytoplasmic membrane, because of the type of reaction it catalyses and the fact that it lacks a signal peptide sequence. Hence, GtrB is not likely to be involved in the UndP-Glc translocation. Three possibilities remain in terms of the translocation of lipid-linked glucose: (a) only GtrA is involved, (b) both GtrA and GtrX are involved, (c) only GtrX is involved. As described above, GtrX is also a very hydrophobic protein with 10 or more potential transmembrane domains. Its hydrophobicity plot is similar to a number of Wzx, Wzy and RfaL proteins, perhaps because they all interact with UndP and function in a hydrophobic environment. Also, based on the method of Von Heijne (1985), a potential signal peptide sequence was identified at the $\mathrm{N}$ terminus of GtrX, suggesting that it was largely a periplasmic membrane protein, or that its active site was at the periplasmic face. Nevertheless, since the type of reaction it catalyses (to position the glucosyl molecules and release UndP) and the fact that GtrA can enhance the lysis function of GtrB (presumably due to the translocation of lipid-Glc), we believe that (c) is not likely, although GtrX may be involved in translocation of the free UndP back to the cytoplasmic face of the inner membrane. At this point we are unable to determine whether $(a)$ or $(b)$ is correct.

The lysis phenomenon described raised a question why did GtrB slow the growth rate of the cell and result in cell lysis when treated with a low osmolarity solution? Since the function of GtrB is now clear, we feel a possible explanation of the lysis phenomenon is to be found in the shortage of free bactoprenol lipid on the bacterial cytoplasmic membrane. It has long been known that the bactoprenol lipid carrier is also used in the biosynthesis pathways of many other bacterial outermembrane structures, such as LPS, murein (peptidoglycan), capsular $\mathrm{K}$ antigen, enterobacterial common antigen (ECA), lipoteichoic acid and possibly membrane-derived oligosaccharide (MDO) (Harkness \& Braun, 1989; Harkness et al., 1990; Kennedy, 1987; Weissborn et al., 1991). Bactoprenol-like substances have also been isolated from a number of plants and the liver of animals. It is thought that these compounds are cofactors in the biosynthesis of complex carbohydrates in both prokaryotic and eukaryotic cells, facilitating the membrane-associated assembly and transportation of oligosaccharides. There is an exquisite balance between Und, UndP and UndPP in the membrane. The bactoprenol pool on the bacterial membrane is also limited and recycling is required to keep the cell physiologically healthy (Harkness \& Braun, 1989). In this study, when only GtrB was present, UndP-Glc accumulated (presumably on the cytoplasmic side of the inner membrane) 


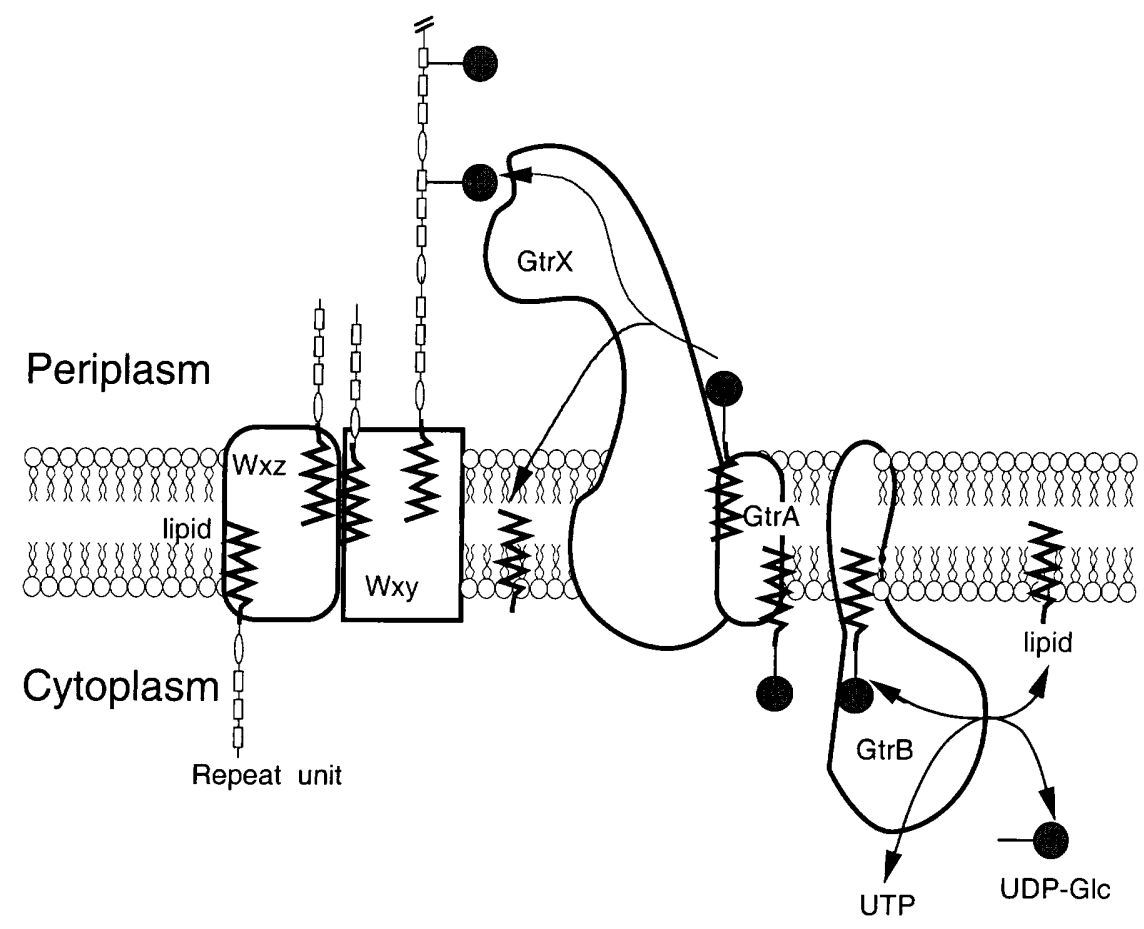

Fig. 5. A hypothetical model of glucosylation process of S. flexneri LPS by phage SfX. First, the glucosyl residue is transferred from UDP-Glc to membrane-anchored lipid (UndP). Second, the lipid-linked glucose is flipped out by either GtrA alone, or by GtrA in association with GtrX. Third, the glucosyl residue is positioned onto Rhal on the partially polymerized $O$ side chain, which is still linked to the lipid.

since no GtrX was available to release the UndP for recycling. Consequently, the biosynthesis of other bacterial outer-membrane components was affected. The net result was that GtrB indirectly changed the normal physiology of the bacterial cell wall. Therefore, the bacteria became sensitive to low osmolarity solutions. Since the formation of UndP-Glc catalysed by GtrB is a reversible reaction (Nikaido et al., 1971), it is reasonable to think that $\mathrm{GtrB}$ alone can cause some slight lysis. However, if the function of GtrA is to associate with the translocation of UndP-Glc across the cytoplasmic membrane, it would not be surprising that GtrA increases the UndP pool crisis and thus increases the lytic action of GtrB. Further investigation of the precise function of GtrA is hindered by the lack of an appropriate method to characterize the translocation of UndP- $\beta$-Glc across the cytoplasmic membrane. The study of UndP- $\beta$ Glc translocation is further complicated by the fact that glucosyl modification also occurs in the biosynthesis pathway of many other cell components located outside the bacterial inner membrane (such as the core oligosaccharide of LPS and the MDO). Because of the high background, attempts to label the cells (SFL124, SFL1195 and JM109) with $\left[{ }^{14} \mathrm{C}\right]$ glucose and subsequently detect the accumulation of UndP- $\beta-\left[{ }^{14} \mathrm{C}\right]$ glucose intermediates at the cytoplasmic side of the inner membrane were unsuccessful.

Since GtrX alone can still mediate a partial conversion, we postulate that there must be other host-encoded glucose transportation pathways in S. flexneri SFL124. This pathway can ineffectively complement the defect of GtrA and GtrB, therefore resulting in partial $O$ antigen conversion. We believe that the lipid-linked glucose formed by this pathway is slightly different from the UndP- $\beta$ Glc formed by GtrB, or simply that the amount is insufficient to complement the defect of GtrA or GtrB.

We hypothesize that the pathway of the LPS glucosylation process mediated by $S$. flexneri bacteriophage SfX is composed of three steps (Fig. 5). In the first step, GtrB catalyses the formation of the UndP-Glc intermediate from UDP-Glc and UndP. Like the formation of $\mathrm{O}$ antigen repeat units, this step takes place at the cytoplasmic side of the cytoplasmic membrane. In the second step, UndP-Glc is translocated to the periplasmic face either by GtrA alone or by GtrA associated with GtrX. Finally, the glucosyl group is positioned on the correct sugar residue in the growing polysaccharide side chain by GtrX while this chain is still linked to the antigen-carrier lipid (ACL). Since the glucosylation only happens to at least the second repeat unit from the growing end (Helander et al., 1992; Takeshita \& Makela, 1971), the proximal repeat unit from the ACL is not altered by this modification. Therefore, the same Wzy polymerase is still able to catalyse $\mathrm{O}$ antigen polymerization and subsequently the same WaaL ligase can still transfer the polysaccharides to the core oligosaccharide. The lipid carrier used by the glucosylation process is shared with other bacterial outer-membrane 
structure biosynthesis pathway(s) and regeneration of these molecules is required for the normal function of the bacterial cells.

\section{ACKNOWLEDGEMENTS}

We thank Inger Falt for the $r f b^{-}$strain of S. flexneri, Nils Carlins for monoclonal antibodies and John Mekalanos for pGP704. This work was supported by a grant from the National Health and Medical Research Council of Australia.

\section{REFERENCES}

Ackermann, H. W. \& DuBow, M. S. (1987). Viruses of Prokaryotes. Florida: CRC Press.

Amor, P. A. \& Whitfield, C. (1997). Molecular and functional analysis of genes required for expression of group IB K antigens in Escherichia coli: characterization of the his-region containing gene clusters for multiple cell-surface polysaccharides. Mol Microbiol 26, 145-161.

Bastin, D. A., Stevenson, G., Brown, P. K., Haase, A. \& Reeves, P. R. (1993). Repeat unit polysaccharides of bacteria: a model for polymerization resembling that of ribosomes and fatty acid synthetase, with a novel mechanism for determining chain length. Mol Microbiol 7, 725-734.

Blattner, F. R., Plunkett, G., Bloch, C. A. \& 14 other authors (1997). The complete genome sequence of Escherichia coli K-12. Science 277, 1453-1474.

Clarke, B. R. \& Whitfield, C. (1992). Molecular cloning of the $r f b$ region of Klebsiella pneumoniae serotype O1:K20: the $r f b$ gene cluster is responsible for synthesis of the D-galactan I O polysaccharide. J Bacteriol 174, 4614-4621.

Falt, I. C., Schweda, E. K., Klee, S., Singh, M., Floderus, E., Timmis, K. N. \& Lindberg, A. A. (1995). Expression of Shigella dysenteriae serotype $1 \mathrm{O}$-antigenic polysaccharide by Shigella flexneri aroD vaccine candidates and different $S$. flexneri serotypes. J Bacteriol 177, 5310-5315.

Harkness, R. E. \& Braun, V. (1989). Colicin M inhibits peptidoglycan biosynthesis by interfering with lipid carrier recycling. $J$ Biol Chem 264, 6177-6182.

Harkness, R. E., Fiedler, W. \& Braun, V. (1990). Lack of inhibition by colicin $M$ suggests bactoprenol independence of MDO biosynthesis. FEBS Lett 262, 245-248.

Helander, I. M., Moran, A. P. \& Makela, P. H. (1992). Separation of two lipopolysaccharide populations with different contents of Oantigen factor 122 in Salmonella enterica serovar typhimurium. Mol Microbiol 6, 2857-2862.

Hitchcock, P. J. \& Brown, T. M. (1983). Morphological heterogeneity among Salmonella lipopolysaccharide chemotypes in silver-stained polyacrylamide gels. J Bacteriol 154, 269-277.

Huan, P. T., Taylor, R., Lindberg, A. A. \& Verma, N. K. (1995). Immunogenicity of the Shigella flexneri serotype Y (SFL124) vaccine strain expressing cloned glucosyl transferase gene of converting bacteriophage SfX. Microbiol Immun 39, 467-472.

Huan, P. T., Bastin, D. A., Whittle, B. L., Lindberg, A. A. \& Verma, N. K. (1997a). Molecular characterisation of the genes involved in $\mathrm{O}$-antigen modification, attachment, integration and excision in Shigella flexneri bacteriophage SfV. Gene 195, 217-227.

Huan, P. T., Whittle, B. L., Bastin, D. A., Lindberg, A. A. \& Verma, N. K. (1997b). Shigella flexneri type-specific antigen V: cloning, sequencing and characterization of the glucosyl transferase gene of temperate bacteriophage SfV. Gene 195, 207-216.
Ielpi, L., Couso, R. O. \& Dankert, M. A. (1993). Sequential assembly and polymerization of the polyprenol-linked pentasaccharide repeating unit of the xanthan polysaccharide in Xanthomonas campestris. J Bacteriol 175, 2490-2500.

Jackson, E. N., Jackson, D. A. \& Deans, R. J. (1978). EcoRI analysis of bacteriophage P22 DNA packaging. J Mol Biol 118, 365-388.

Jiang, X. M., Neal, B., Santiago, F., Lee, S. J., Romana, L. K. \& Reeves, P. R. (1991). Structure and sequence of the $r f b$ ( $O$ antigen) gene cluster of Salmonella serovar typhimurium (strain LT2). Mol Microbiol 5, 695-713.

Keenleyside, W. J. \& Whitfield, C. (1996). A novel pathway for Opolysaccharide biosynthesis in Salmonella enterica serovar borreze. J Biol Chem 271, 28581-28592.

Kennedy, E. P. (1987). Membrane-derived oligosaccharides. In Escherichia coli and Salmonella typhimurium: Cellular and Molecular Biology, pp. 648-679. Edited by E. P. Kennedy, F. C. Neidhardt, J. L. Ingraham, K. B. Low, B. Magasanik, M. Schaechter \& H. E. Umbarger. Washington, DC: American Society for Microbiology.

Kessler, A. C., Brown, P. K., Romana, L. K. \& Reeves, P. R. (1991). Molecular cloning and genetic characterization of the $r f b$ region from Yersinia pseudotuberculosis serogroup IIA, which determines the formation of the 3,6-dideoxyhexose abequose. J Gen Microbiol 137, 2689-2695.

Klena, J. D. \& Schnaitman, C. A. (1993). Function of the $r f b$ gene cluster and the $r f e$ gene in the synthesis of $\mathrm{O}$ antigen by Shigella dysenteriae 1. Mol Microbiol 9, 393-402.

Klena, J. D., Ashford, R. S. \& Schnaitman, C. A. (1992). Comparison of the lipopolysaccharide biosynthesis genes $r f a K$, rfaL, rfaY and rfaZ of Escherichia coli K-12 and S. typhimurium. J Bacteriol 174, 7297-7303.

Lindberg, A. A. (1977). Bacterial Surface Polysaccharides and Phage Adsorption. New York: Academic Press.

Liu, D., Cole, R. A. \& Reeves, P. R. (1996). An O-antigen processing function for $\mathrm{Wzx}(\mathrm{RfbX})$ : a promising candidate for $\mathrm{O}$-unit flippase. J Bacteriol 178, 2102-2107.

McGrath, B. C. \& Osborn, M. J. (1991). Localization of the terminal steps of $\mathrm{O}$-antigen synthesis in Salmonella typhimurium. J Bacteriol 173, 649-654.

MacLachlan, P. R., Kadam, S. K. \& Sanderson, K. E. (1991). Cloning, characterization and DNA sequence of the $r f a K K$ region for lipopolysaccharide synthesis in Salmonella typhimurium LT2. J Bacteriol 173, 7151-7163.

Macpherson, D. F., Manning, P. A. \& Morona, R. (1994). Characterization of the dTDP-rhamnose biosynthetic genes encoded in the $r f b$ locus of Shigella flexneri. Mol Microbiol 11, 281-292.

Makela, P. H. (1973). Glucosylation of lipopolysaccharide in Salmonella: mutants negative for $\mathrm{O}$ antigen factor 122.J Bacteriol 116, 847-856.

Makela, P. H. \& Stocker, B. A. D. (1984). Nonessential modifications of the $\mathrm{O}$ polysaccharide. In Handbook of Endotoxin, pp. 100-108. Edited by E. Rietschel. New York: Elsevier.

Mavris, M., Manning, P. A. \& Morona, R. (1997). Mechanism of bacteriophage SfII-mediated serotype conversion in Shigella flexneri. Mol Microbiol 26, 939-950.

Miller, V. L. \& Mekalanos, J. J. (1988). A novel suicide vector and its use in construction of insertion mutations: osmoregulation of outer membrane proteins and virulence determinants in Vibrio cholerae requires toxR. J Bacteriol 170, 2575-2583.

Morona, R., Mavris, M., Fallarino, A. \& Manning, P. A. (1994). Characterization of the $r f c$ region of Shigella flexneri. J Bacteriol 176, 733-747. 
Morona, R., van den Bosch, L. \& Manning, P. A. (1995). Molecular, genetic and topological characterization of $\mathrm{O}$-antigen chain length regulation in Shigella flexneri. J Bacteriol 177, 1059-1068.

Muhlradt, P. F. \& Golecki, J. R. (1975). Asymmetrical distribution and artifactual reorientation of lipopolysaccharide in the outer membrane bilayer of Salmonella typhimurium. Eur J Biochem 51, 343-352.

Muhlradt, P. F., Menzel, J., Golecki, J. R. \& Speth, V. (1973). Outer membrane of Salmonella. Sites of export of newly synthesised lipopolysaccharide on the bacterial surface. Eur J Biochem 35, 471-481.

Mulford, C. A. \& Osborn, M. J. (1983). An intermediate step in translocation of lipopolysaccharide to the outer membrane of Salmonella typhimurium. Proc Natl Acad Sci USA 80, 1159-1163.

Nikaido, H., Nikaido, K., Nakae, T. \& Makela, P. H. (1971). Glucosylation of lipopolysaccharide in Salmonella: biosynthesis of $\mathrm{O}$ antigen factor 12 2. I. Overall reaction. J Biol Chem 246, 3902-3911.

Nikaido, K. \& Nikaido, H. (1971). Glucosylation of lipopolysaccharide in Salmonella : biosynthesis of $\mathrm{O}$ antigen factor 122 . II. Structure of the lipid intermediate. J Biol Chem 246, 3912-3919.

Rogers, H. J., Perkins, H. R. \& Ward, J. B. (1980). Microbial Cell Walls and Membranes. London: Chapman \& Hall.

Sambrook, J., Fritsch, E. F. \& Maniatis, T. (1989). Molecular Cloning: a Laboratory Manual, 2nd edn. Cold Spring Harbor, NY: Cold Spring Harbor Laboratory.

Sasaki, T., Uchida, T. \& Kurahashi, K. (1974). Glucosylation of Oantigen in Salmonella carrying epsilon 15 and epsilon 34 phages. J Biol Chem 249, 761-772.

Schnaitman, C. A. \& Klena, J. D. (1993). Genetics of lipopolysaccharide biosynthesis in enteric bacteria. Microbiol Rev 57, $655-682$.

Simmons, D. A. \& Romanowska, E. (1987). Structure and biology of Shigella flexneri O antigens. J Med Microbiol 23, 289-302.

Streisinger, G., Emrich, J. \& Stahl, M. M. (1967). Chromosomal structure in phage T4. III. Terminal redundancy and length determination. Proc Natl Acad Sci USA 57, 292-295.
Stroeher, U. H., Parasivam, G., Dredge, B. K. \& Manning, P. A. (1997). Novel Vibrio cholerae O139 genes involved in lipopolysaccharide biosynthesis. J Bacteriol 179, 2740-2747.

Takeshita, M. \& Makela, P. H. (1971). Glucosylation of lipopolysaccharide in Salmonella: biosynthesis of $\mathrm{O}$ antigen factor 122. III. The presence of 122 determinants in haptenic polysaccharides. $J$ Biol Chem 246, 3920-3927.

Tye, B. K., Huberman, J. A. \& Botstein, D. (1974). Non-random circular permutation of phage P22 DNA. J Mol Biol 85, 501-532.

Verma, N. K., Brandt, J. M., Verma, D. J. \& Lindberg, A. A. (1991). Molecular characterization of the $\mathrm{O}$-acetyl transferase gene of converting bacteriophage SF6 that adds group antigen 6 to Shigella flexneri. Mol Microbiol 5, 71-75.

Verma, N. K., Verma, D. J., Huan, P. T. \& Lindberg, A. A. (1993). Cloning and sequencing of the glucosyl transferase-encoding gene from converting bacteriophage X (SFX) of Shigella flexneri. Gene 129, 99-101.

Von Heijne, G. (1985). Signal sequences: the limits of variation. $J$ Mol Biol 184, 99-105.

Weissborn, A. C., Rumley, M. K. \& Kennedy, E.P. (1991). Biosynthesis of membrane-derived oligosaccharides: membranebound glucosyltransferase system from Escherichia coli requires polyprenyl phosphate. J Biol Chem 266, 8062-8067.

Whitfield, C. (1995). Biosynthesis of lipopolysaccharide $\mathrm{O}$ antigens. Trends Microbiol 3, 178-185.

Whitfield, C., Amor, P. A. \& Koplin, R. (1997). Modulation of surface architecture of Gram-negative bacteria by the action of surface polymer:lipid A-core ligase and by determinants of polymer chain length. Mol Microbiol 23, 629-638.

Wright, A. (1971). Mechanism of conversion of the Salmonella $\mathrm{O}$ antigen by bacteriophage epsilon 34. J Bacteriol 105, 927-936.

Yanisch-Perron, C., Vieira, J. \& Messing, J. (1985). Improved M13 phage cloning vectors and host strains: nucleotide sequences of the M13mp18 and pUC19 vectors. Gene 33, 103-119.

Received 3 December 1998; accepted 18 January 1999. 